\title{
Medikamentell behandling av menstruasjonsrelaterte plager
}

\author{
Ikke-steroide antiinflammatoriske midler (NSAID) har dokumentert \\ effekt på både dysmenoré og menoragi, og det er ikke vist forskjeller \\ i effekt mellom de ulike preparatene. Behandlingen bør starte umiddel- \\ bart ved smertedebut og gis i tilstrekkelig høy dose. NSAID-preparatene \\ virker blødningsbegrensende ved menoragi, men er mindre effektive \\ enn traneksamsyre og gestagenholdige livmorinnlegg.
}

Se også kunnskapsprøve på www.tidsskriftet.no/quiz

\section{Kari Hilde Juvkam \\ khjuvkam@online.no \\ Grimstad Legesenter \\ Hilde Beate Gudim \\ Skui legekontor}

Dysmenoré, eller menstruasjonssmerter, forekommer hyppig hos unge kvinner med etablert ovulasjon og er en vanlig årsak til fravær fra skole og arbeidsplass (1). Menoragi er regelmessige, men rikelige og/eller langvarige menstruasjonsblødninger $(2,3)$. Artikkelen omtaler medikamentell behandling av dysmenoré og menoragi med hovedvekt på ikke-steroide antiinflammatoriske midler.

\section{Materiale og metode}

Det er foretatt et ikke-systematisk søk i PubMed begrenset til oversiktsartikler eller randomiserte og kontrollerte studier på norsk eller engelsk. Det ble gjort et skjønnsmessig utvalg av artikler basert på forfatternes erfaringer innen feltet.

\section{Ikke-steroide antiinflammatoriske midler Virkningsmekanisme}

Ikke-steroide antiinflammatoriske midler, heretter omtalt som NSAID-preparater, reduserer syntesen av prostaglandin gjennom en reversibel hemning av enzymet cyklooksygenase (COX) (fig 1). Det finnes i to former, cyklooksygenase-1 (COX-1), som er det konstitusjonelt forekommende enzymet, og cyklooksygenase-2 (COX-2) som induseres av inflammasjon. NSAID-preparater har analgetisk og antipyretisk effekt i tillegg til den antiinflammatoriske effekten. De kan også være nyttige som smertestillende medikamenter der inflammasjon ikke er en viktig del av smertegenesen, som ved menstruasjonssmerter (4). Prostaglandiner produseres lokalt $\mathrm{i}$ endometriet og utløser uteruskontraksjoner som gir smerter. Kvinner med store menstruasjonsblødninger har høyere innhold av prostaglandinene $\mathrm{E}_{2}$ og $\mathrm{F}_{2 \mathrm{a}} \mathrm{i}$ endometriet sammenliknet med kvinner som har normal menstruasjon $(4,5)$. Prostaglandiner har vasodilaterende effekt, og NSAID-preparaters blokkerende effekt på prostaglandinsyntesen kan redusere blødning lokalt i endometriet (6).

\section{Metabolisme}

NSAID-preparater absorberes hurtig og nesten fullstendig fra mage-tarm-kanalen med maksimal plasmakonsentrasjon innen 1-4 timer. Plasmaproteinbindingsgraden er høy og biotilgjengeligheten tilnærmet $100 \%$ ved oral tilførsel. De metaboliseres i leveren ved CYP1A2 og CYP2C9 og utskilles hovedsakelig via nyrene. Enterotabletter har forsinket absorpsjon og bør ikke benyttes når man ønsker raskt innsettende effekt (6).

\section{Bivirkninger}

De hyppigst opplevde bivirkningene av NSAID-preparater er hodepine og kvalme. Hemming av COX-1 gir reduksjon av blodplatenes aggregering og redusert produksjon av prostaglandiner med protektiv effekt på mageslimhinnen. Dette vil kunne medføre øt blødningstendens og økt risiko for gastrointestinale blødninger (6-8). Denne effekten er doseavhengig, og risikoen øker sterkt med stigende alder. Kliniske observasjoner og undersøkelser tyder på at NSAIDpreparater kan føre til midlertidig infertilitet (9). Forskrivning av NSAID-preparater må veies opp mot risiko for alvorlige bivirkninger, især gastrointestinale blødninger. Behandlingstiden bør derfor være kortest mulig.

\section{Dysmenoré}

Primcer dysmenoré er menstruasjonssmerter uten bakenforliggende organisk sykdom og skyldes en funksjonell forstyrrelse i endometriet knyttet til menstruasjonen. Angivelse av prevalens blant kvinner i menstruerende alder i Norden er rundt 50-73\% (10). Av disse kvinnene er 10-15\% så smerteplaget at de er arbeidsuføre én til flere dager per måned (11). Primær dysmenoré ses hyppigst når ovulasjonen er etablert, noen måneder til år etter menarke. Ved økende dysmenoré tross igangsatt behandling henvises kvinnene til ultralyd for å utelukke hematometra.

Økt produksjon av prostaglandiner, leukotriener og vasopressin lokalt $i$ endometriet er assosiert med dysmenoré. En økt produksjon eller ubalanse i prostaglandiner og muligens eikosanoider som frigjøres fra endometriet under menstruasjonen utløser kraftige uteruskontraksjoner med redusert blodgjennomstrømning i uterus samt økt smertefølsomhet i nervefibrene i uterus ( 1 , 5). Dette medfører krampeliknende smerter i mage, korsrygg, innside av lår og lysker. Ledsagersymptomer kan være kvalme, brekninger og eventuelt diaré samt ofte hodepine, irritabilitet og søvnforstyrrelse.

Sekundcer dysmenoré opptrer gjerne i 30-40 årsalderen, og det kan påvises organisk årsak som endometriose, myomer, bekkeninfeksjon eller livmorinnlegg. Ved sekundær dysmenoré bør bakenforliggende årsak avklares før behandling.

\section{Behandling av primær dysmenoré}

Symptomlindrende behandling ved primær dysmenoré retter seg primært mot å påvirke de fysiologiske mekanismene bak menstruasjonssmertene, slik som prostaglandinproduksjonen. NSAID-preparater har overbevisende smertestillende effekt ved dysmenoré sammenliknet med placebo $(4,12,13)$, og behandlingen øker evnen til å være i aktivitet

\section{Hovedbudskap}

- Ikke-steroide antiinflammatoriske midler (NSAID-preparater) har dokumentert effekt ved dysmenoré og menoragi

- Kvinnene bør gjøres oppmerksom på aktuelle bivirkninger, især fra gastrointestinalkanalen

- Ved utilstrekkelig effekt kan østrogenholdige $p$-piller eller gestagenholdig livmorinnlegg forsøkes

- Ved ren menoragi er traneksamsyre et godt alternativ 
(14). Når ulike NSAID-preparater sammenliknes med hverandre eller med paracetamol, er det ikke kunnskapsgrunnlag for at ett NSAID-preparat er bedre enn et annet i forhold til effekt og bivirkninger, men NSAIDpreparater synes mer effektive enn paracetamol $(4,10,12)$. Vurderingene er imidlertid noe usikre, fordi studiepopulasjonene delvis er for små og uegnet for metaanalyse. I tillegg er mange studier gjort med medikamenter som ikke er tilgjengelige i Norge. Farmasøytisk industri har initiert og/eller delvis finansiert flere av studiene (4).

Ved dysmenoré må NSAID-preparater tas straks ved symptomdebut og i tilstrekkelig høy startdose for optimal effekt (tab 1) $(6,15$, 16). Det skal tilstrebes kortest mulig behandlingstid og kvinnen skal gjøres oppmerksom på mulige bivirkninger av medikamentet.

Alternativt kan østrogenholdige p-piller eller gestagenholdig livmorinnlegg forsøkes $(5,13,17)$. P-piller virker ved å hemme ovulasjonen og gir et tynnere endometrium, og gestagenholdig livmorinnlegg hemmer vekst av endometriet. Begge alternativene reduser prostaglandinproduksjonen $(5,13)$. Dersom det ikke foreligger kontraindikasjoner, kan østrogenholdige p-piller anbefales kvinner som ikke tolererer eller har hatt effekt av NSAID-preparater gjennom tre behandlingssykluser. P-piller med forlenget syklus, dvs. p-piller tatt kontinuerlig gjennom 3-6 måneder, er et alternativ for kvinner som har uttalte plager (17). Dersom kvinnen verken har hatt effekt av NSAIDpreparater, gestagenholdig livmorinnlegg eller p-piller innen seks måneder, bør hun henvises til gynekolog for vurdering av mulig endometriose (13).

\section{Menoragi}

Menoragi er rikelige, regelmessige menstruasjonsblødninger med mer enn $80 \mathrm{ml}$ per menstruasjon og/eller mer enn åtte dager med blodtap som har betydning for kvinnens livskvalitet. Det rammer 9-14\% av ellers friske kvinner i aldersgruppen 30-49 år, og i $80 \%$ av tilfellene finnes ingen påvisbar årsak (3). Blodtapet kan resultere i anemi, tretthet, slapphet og synkope. Det er påvist

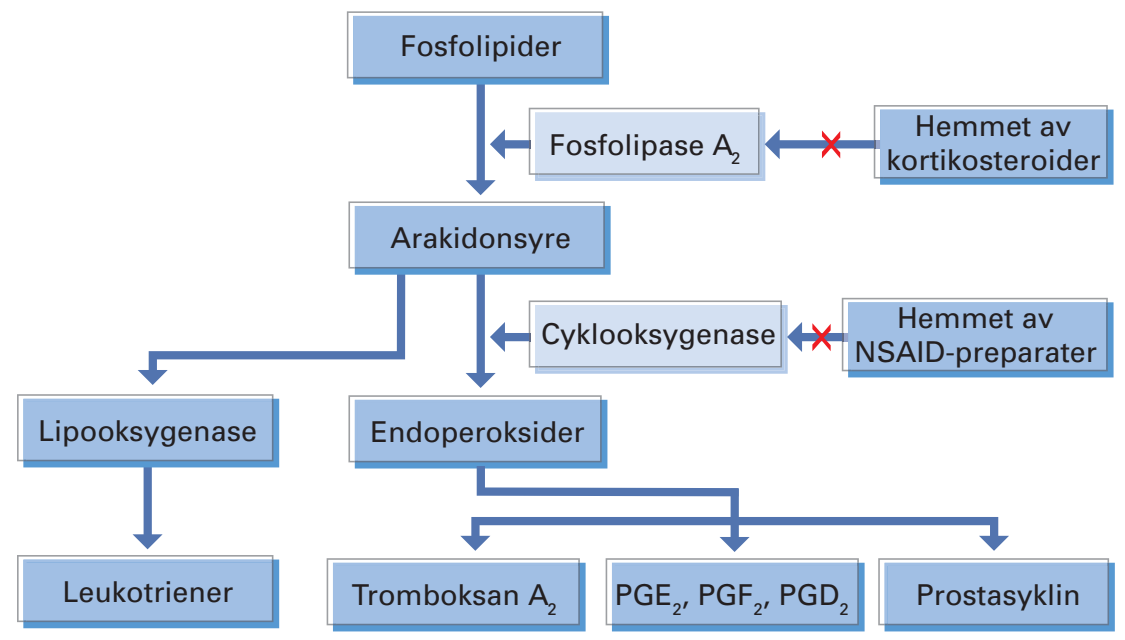

Figur 1 Virkningsmekanismen for ikke-steroide antiinflammatoriske midler (NSAID-preparater). PGE = prostaglandin type $E_{2}, P G F_{2}=$ prostaglandin type $F_{2}, P G D_{2}=$ prostaglandin type $D_{2}$

høyere nivå av plasminogenaktivatorer i endometriet hos kvinner med kraftige menstruasjonsblødninger (18).

Vanlige årsaker hos de resterende $20 \%$ er endokrin forstyrrelse som hypo- og hypertyreose, myom(er) eller kobberholdig livmorinnlegg. Menoragi er i sjeldne tilfeller tegn på cancer eller en koagulasjonsforstyrrelse. En medfødt koagulasjonsforstyrrelse, vanligst er von Willebrands sykdom, kan som første symptom gi rikelige menstruasjonsblødninger etter menarke.

\section{Behandling av menoragi}

Ved menoragi der det ikke påvises bakenforliggende organisk sykdom, skal medikamentell behandling alltid forsøkes før eventuell kirurgisk intervensjon. En rekke medikamenter er tilgjengelige, slik som NSAIDpreparater og traneksamsyre, som tas i forbindelse med menstruasjonen, og østrogenholdige p-piller og gestagenholdig livmorinnlegg.

NSAID-preparater reduserer blødning med ca. $20 \%$ samtidig som eventuell dysmenoré behandles (2). Som gruppe er NSAID-preparater mer effektive enn placebo, men mindre effektive enn traneksamsyre $(2,18,19)$. De ulike NSAID-preparater er likeverdige og har effekt uavhengig av årsaken til blødningene $(18,19)$. De er også effektive ved dysfunksjonelle blødninger (anovulatoriske blødninger/ svikt i hormonell balanse) (2).

Store blødninger og smerte er de vanligste årsakene til at kvinner ikke ønsker å bruke eller ønsker å fjerne kobberholdig livmorinnlegg. Studier av kvinner med slike livmorinnlegg har vist at NSAID-preparater også hos disse kvinnene gir reduksjon av menstruasjonsblødning uavhengig av grad av blødning (20).

Traneksamsyre, som har antifibrinolytisk effekt, er et godt alternativ til NSAID-preparater. Brukt i adekvat dose på $1-1,5 \mathrm{~g} \mathrm{3-4}$ ganger daglig reduseres blødning generelt under menstruasjonen med rundt $50 \%$ (19). Det er ikke påvist økt insidens av tromboembolisk sykdom hos kvinner behandlet med traneksamsyre $(18,19)$.

Østrogenholdige p-piller reduserer blødningsmengde på linje med NSAID-preparater og er aktuell behandling dersom det ikke foreligger kontraindikasjoner og særlig der kvinnen har behov for prevensjon $(21,22)$.

Tabell 1 NSAID-preparater ved dysmenoré og menoragi. Basert på Felleskatalogen og Norsk Legemiddelhåndbok $(6,16)$

\begin{tabular}{|c|c|c|c|c|}
\hline Substans & Generisk navn & Dosering & Tilgjengelighet & Indikasjon \\
\hline Eddiksyrederivater & Diklofenak & $50 \mathrm{mg}$ 2-3 ganger daglig i inntil fire dager & Resept & Dysmenoré \\
\hline \multirow[t]{2}{*}{ Propionsyrederivater } & Ibuprofen & $\begin{array}{l}\text { Initialt } 400-800 \mathrm{mg} \text {, deretter } 400 \mathrm{mg} \text { hver } \\
\text { 6. }-8 \text {. time etter behov' }\end{array}$ & Håndkjøp & Dysmenoré \\
\hline & Naproxen & $\begin{array}{l}\text { Dysmenoré: } 1 \text {. dose } 500 \text { mg, deretter } 250 \text { mg v.b. } \\
\text { Maksimalt } 1250 \mathrm{mg} \text { per døgn² } \\
\text { Menoragi: } 1 \text {. dag: } 750-1250 \mathrm{mg} \text { fordelt på to } \\
\text { doser, deretter } 500-1000 \mathrm{mg} \text { daglig fordelt på } \\
\text { to doser }\end{array}$ & Håndkjøp & $\begin{array}{l}\text { Dysmenoré og menoragi } \\
\text { Det eneste NSAID-preparat regis- } \\
\text { trert med menoragi som indikasjon }\end{array}$ \\
\hline Oksikamer & Meloksikam & 1. dose $15 \mathrm{mg}$, deretter $7,5 \mathrm{mg} \times 1-2$ daglig & Resept & $\begin{array}{l}\text { Menoragi, men ikke registrert } \\
\text { for denne indikasjon i Norge }\end{array}$ \\
\hline
\end{tabular}


Gestagenholdig livmorinnlegg gir opptil $90 \%$ redusert blødning, og ca. $30 \%$ blir blødningsfrie. Dette er et godt alternativ ved menoragi med eller uten prevensjonsbehov (23). Gestagen i tablettform forskrives hyppig for menoragi, men kortsyklisk (intermitterende) behandling har liten blødningsbegrensende effekt (24). Dersom det er ønskelig med gestagen, må medikamentet administreres som langsyklisk (kontinuerlig) behandling. Denne behandlingen er forbundet med bivirkninger som kvalme, blødningsforstyrrelser og væskeretensjon, og etterlevelsen kan være dårlig. Endometriedestruksjon er effektiv behandling og er aktuelt dersom medikamentell behandling ikke gir ønsket resultat. Hysterektomi forbeholdes terapiresistente tilstander (25).

\section{Konklusjon}

NSAID-preparater er effektive i behandlingen av dysmenoré, synes mer effektive enn paracetamol, og det er ikke dokumentert større forskjeller i effektivitet eller sikkerhet mellom ulike NSAID-preparater. Kvinnen må gjøres oppmerksom på aktuelle bivirkninger. Dersom kvinnen ikke har effekt av NSAID-preparater i løpet av tre menstruasjonssykluser, skal man vurdere alternativ behandling, som østrogenholdige p-piller eller gestagenholdig livmorinnlegg.

Ved menoragi er traneksamsyre og gestagenholdig livmorinnlegg mer effektive enn NSAID-preparater. Medikamentell behandling skal være forsøkt før kirurgisk behandling vurderes ved menoragi.

\section{Kari Hilde Juvkam (f. 1953)}

er spesialist i allmennmedisin. Hun er fastlege i Grimstad og universitetslektor ved Universitetet i Oslo samt leder av referansegruppen for gynekologi i Norsk forening for allmennmedisin. Ingen oppgitte interessekonflikter.

\section{Hilde Beate Gudim (f. 1954)}

er spesialist i allmennmedisin. Hun er fastlege i Bærum samt praksiskonsulent ved Kvinneklinikken, Bærum sykehus. Hun har skrevet to bøker i gynekologi sammen med Kari Hilde Juvkam. Ingen oppgitte interessekonflikter.

\section{Litteratur}

1. Sundell G, Milsom I, Andersch B. Factors influencing the prevalence and severity of dysmenorrhoea in young women. Br J Obstet Gynaecol 1990; 97 : $588-94$.

2. Lethaby A, Augood C, Duckitt K et al. Nonsteroidal anti-inflammatory drugs for heavy menstrual bleeding. Cochrane Database Syst Rev 2007; nr. 4: CD000400.

3. Rosenfeld JA. Treatment decisions in the management of menorrhagia. Medscape Womens Health 1997; 2: 6 .

4. Marjoribanks J, Proctor M. Farquhar $\mathrm{C}$ et al. Nonsteroidal anti-inflammatory drugs for dysmenorrhoea. Cochrane Database Syst Rev 2010; (nr. 1: CD001751.

5. Dawood MY. Primary dysmenorrhea: advances in pathogenesis and management. Obstet Gynecol 2006; 108: 428-41.
6. Norsk Legemiddelhåndbok for helsepersonell. Bergen: Fagbokforlaget, 2010: 1229-33.

7. Gøtzsche P. Non-steroidal anti-inflammatory drugs. Clin Evid 2001; 6: 894-901.

8. Risser A, Donovan D, Heintzman J et al. NSAID prescribing precautions. Am Fam Physician 2009. 80: $1371-8$

9. Skomvoll JF, Rødevand E, Koksvik HS et al. Reversibel infertilitet ved ikke-steroide antiinflammatoriske midler. Tidsskr Nor Lægeforen 2005; 125 : 1476-8.

10. Milsom I, Minic M, Dawood MY et al. Comparison of the efficacy and safety of nonprescription doses of naproxen and naproxen sodium with ibuprofen, acetaminophen, and placebo in the treatment of primary dysmenorrhea: a pooled analysis of five studies. Clin Ther 2002; 24: 1384-400.

11. Banikarim C, Chacko MR, Kelder SH. Prevalence and impact of dysmenorrhea on Hispanic female adolescents. Arch Pediatr Adolesc Med 2000; 154. 1226-9

12. Zhang WY, Li Wan Po A. Efficacy of minor analgesics in primary dysmenorrhoea: a systematic review. Br J Obstet Gynaecol 1998; 105: 780-9.

13. Proctor M, Farquhar C. Diagnosis and management of dysmenorrhoea. BMJ 2006; 332: 1134-8.

14. Chantler I, Mitchell D, Fuller A. Diclofenac potassium attenuates dysmenorrhea and restores exercise performance in women with primary dysmenorrhea. J Pain 2009; 10: 191-200.

15. Harel Z. Dysmenorrhea in adolescents and young adults: from pathophysiology to pharmacological treatments and management strategies. Expert Opin Pharmacother 2008; 9: 2661-72.

16. Felleskatalogen. Antiinflammatoriske og antirevma tiske midler. www.felleskatalogen.no/ (13.3.2011]

17. Kvan E, Narum S. P-piller med forlenget syklus et fremskritt? Tidsskr Nor Lægeforen 2005; 125: 2202-3.

18. Lethaby A, Farquhar C, Cooke I. Antifibrinolytics for heavy menstrual bleeding. Cochrane Database Syst Rev 2000; nr. 3: CD000249.

19. Bonnar J, Sheppard BL. Treatment of menorrhagia during menstruation: randomised controlled trial of ethamsylate, mefenamic acid, and tranexamic acid. BMJ 1996; 313: 579-82.

20. Grimes DA, Hubacher D, Lopez LM et al. Non-steroidal anti-inflammatory drugs for heavy bleeding or pain associated with intrauterine-device use. Cochrane Database Syst Rev 2006; nr. 4: CD006034.

21. Farquhar C, Brown J. Oral contraceptive pill for heavy menstrual bleeding. Cochrane Database Syst Rev 2009; nr. 4: CD000154.

22. Wong $\mathrm{CL}$, Farquhar $\mathrm{C}$, Roberts $\mathrm{H}$ et al. Oral contraceptive pill as treatment for primary dysmenorrhoea. Cochrane Database Syst Rev 2009; nr. 2: CD002120.

23. Lethaby AE, Cooke I, Rees M. Progesterone or progestogen-releasing intrauterine systems for heavy menstrual bleeding. Cochrane Database Syst Rev 2000; nr. 2: CD002126.

24. Lethaby A, Irvine G, Cameron I. Cyclical progestogens for heavy menstrual bleeding. Cochrane Database Syst Rev 2000; nr. 1: CD001016.

25. Fürst SN, Philipsen T, Joergensen JC. Ten-year follow-up of endometrial ablation. Acta Obstet Gynecol Scand 2007; 86: 334-8.

Mottatt 8.3. 2010, første revisjon innsendt 20.8. 2010, godkjent 17.3. 2011. Medisinsk redaktør Mette Sagsveen. 